\title{
An Extrusion Die with Twin Cavities for Semi-hollow Al-Profiles
}

\author{
Xuemei Huang ${ }^{1, a}$, Rurong Deng ${ }^{2, b^{*}}$ \\ 1,2 Guangzhou Vocational College of Science and Technology, Guangzhou, 510550, China \\ aEmail: 41784402@qq.com, bEmail: SQF6410@163.com \\ *The corresponding author
}

\begin{abstract}
The importance of extrusion die with multi-cavities was elaborated. Through an actual case. A new structure for the semi-hollow Al-profiles was introduced. The structure named substituted type to solve the cantilever strength was presented. And the selection and the optimization of structure parameters were described in detail. Including the determination of extrusion machine ability, the layout for the die holes, the use of computer simulation software for analysis and comparison to determine the arrangement of portholes, the structure of chamber in female die, the selection of bearing etc. It was shown that the structure with twin cavities for semi-hollow profiles is effective, the structure can greatly improve the production efficiency and reduce the cost. It is worth promoting. The purpose is to provide reliable data and reference for the further research and development of this technology on the extrusion die with multi-cavities in a die.
\end{abstract}

\section{Introduction}

In recent years, aluminum products have been widely used, and the field of application is more widely. The types and specifications of aluminum alloy products are more and more. The profile of the profiles becomes more and more complex. And in these kinds and specifications, many products are the semi hollow profiles. The design of dies for semi hollow profile is complicated, and the key problem is to solve the die strength. While modern manufacturing technology keeps improving, especially in recent years, the total cost of the enterprises was rising, the enterprises are facing some pressure so that the extrusion technology of multi-cavities in a die is being studied in order to improve production efficiency and reduce costs .

\section{Determination of die structure parameters}

\subsection{The structure form}

This is a substituted type extrusion die structure to make a cut in a reasonable position of the cantilever of semi hollow section. The cantilever is divided into two parts, one part is used as a fake core to design the male die instead of the cantilever in extrusion process, while the other is designed as a die hole of female die. When the male and female die are fitted together and composed of porthole extrusion die, the fake core and die hole recombine in cutting position and reform the integrity of the cantilever, it improves the stress state of the cantilever, the immediate force to the cantilever is changed from the original cantilever to hollow bridge, it greatly improves the strength of the die. For the extrusion die with twin cavities in a die, because each of die core position in the male die is not in the center of the die same as the single hole in the equilibrium of the force around without creating additional pressure difference due to core elastic offset. Therefore, this factor must be taken into account in the die of twin cavities. Otherwise, the offset of the die core will change the wall thickness of the profile. Figure 1. shows a typical semi hollow profile and a schematic diagram for cutting the cantilever into two parts. The section area of the profile is $120 \mathrm{~mm}^{2}$, and its tongue ratio is 5.4 . 


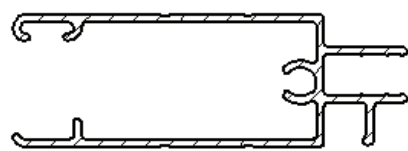

(a) The profile section

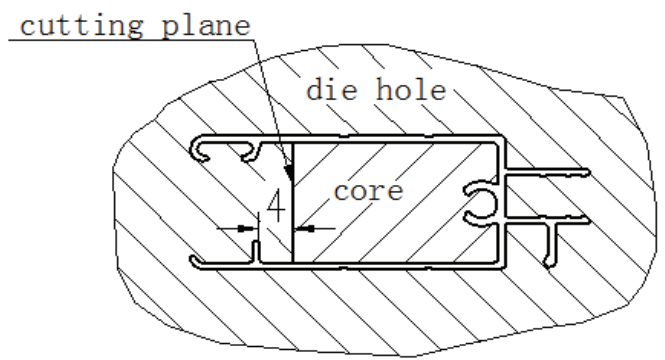

(b) The signal of cantilever cutting

Figure 1. The sketch of section and cantilever division

\subsection{Determination of extrusion machine capacity}

To determine the extrusion machine is to select the proper size of the inner diameter of the extrusion container and the proper pressure of the extrusion machine on the section of the extrusion cylinder. The size of the inner diameter of the extrusion container determines the degree of deformation of the extrusion named extrusion coefficient. The extrusion coefficient is too large, the extrusion force will increase, the extrusion forming will be difficult, and the force that the die will endure will also increase, and the strength of the die will be reduced. The extrusion coefficient is too small, which will affect the mechanical properties and surface quality of the profile. The specific pressure of the extrusion machine is to meet the working pressure for extrusion forming. If the pressure is too small, extrusion forming will be difficult, and the pressure is too high, it will increase the force of the die and reduce the life of the die. Based on the experience, the extrusion coefficient is the most suitable in the range of $40 \sim 80$, while the relative pressure is most favorable at $650 \sim 800 \mathrm{MPa}$. Based on these considerations, for the profiles shown in Figure
1 , the choice of $10 \mathrm{MN}$ extrusion machine is made, the extrusion cylinder diameter is up to $130 \mathrm{~mm}$. By calculation, the extrusion press is $753 \mathrm{MPa}$. If the single hole extrusion is adopted, the extrusion coefficient is 110.6 , which is obviously not suitable, it is suitable for twin cavities with the extrusion coefficient of 55.3.

\subsection{Arrangement of die holes}

Determining the die hole arrangement of twin cavities means to determine the discharge mode of extrusion. The principle of selecting the discharging way is as follows:

One is to ensure that the two hole does not occur interweave, twist, or rub each other in the extrusion process. Two is to consider the choice of die parameters can give full play the potential of the extrusion cylinder. The three is to consider the strength and rigidity of the die.

As a substituted type extrusion die structure with twin cavities, because the core is false, so we must consider the position and direction of the cutting plane in the die, in order to make it possible to cut away from the die center. The layout of the die holes is shown in figure 2.

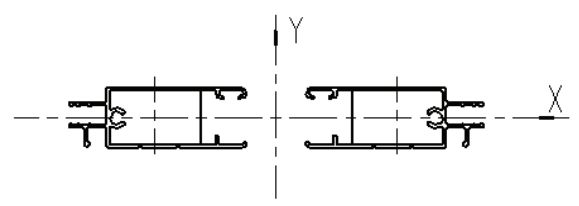

(b)

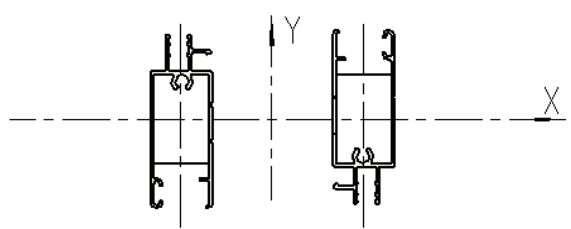

(d)

Figure2. The layout of die hole

The Figure 2- (a) is the most reasonable of the four methods in the diagram. In this way, the large surface of the profile is selected and the contact mode is introduced so as to realize the smooth extrusion. Due to the cutting plane is arranged away from the center, so that when the male and female die reset together, the elastic offset of the core will make the gap of the cutting plane be smaller. According to the plastic forming minimum resistance law, the metal is less likely to enter the joint gap. Thus, the drawing or reinforcing bar of the section can be avoided. 
Figure 2-(b) is just the opposite. For the die of multi cavities, an elastic deviation is caused by the additional pressure difference due to the pressure gradient in the radial direction of the extrusion cylinder, as shown in

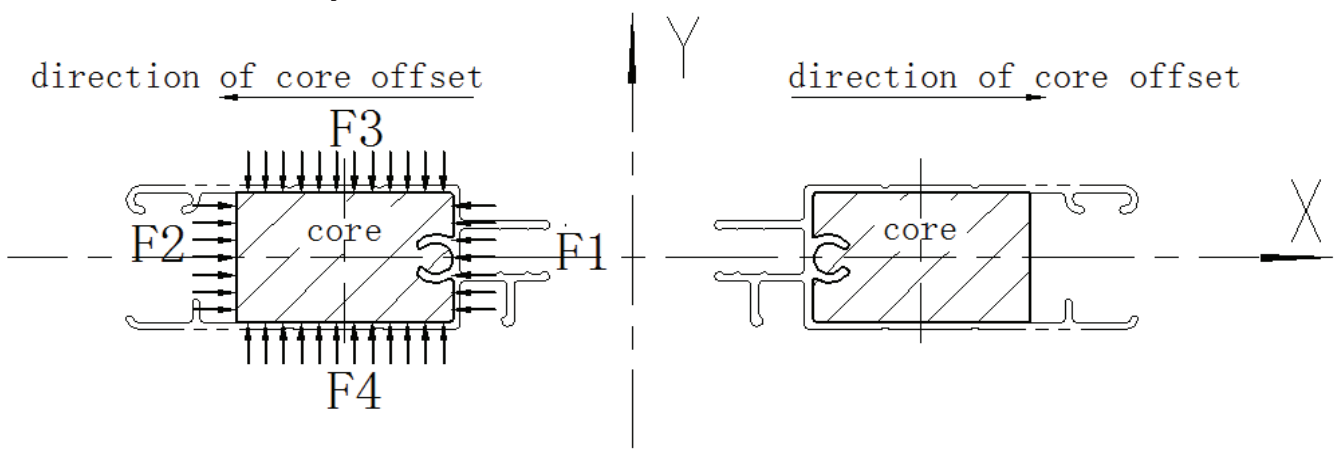

Figure3. The diagram of elastic deviation of die core figure 3 . The force $\mathrm{F} 1$ in the diagram is greater than the force F2, while the force F3 is equal to the force F4.

\section{die}

The parameters of male die include the design of the portholes, the determination of the diversion ratio, and the size selection of the bridge etc.

The arrangement of the feeder ports is shown in figure 4 .

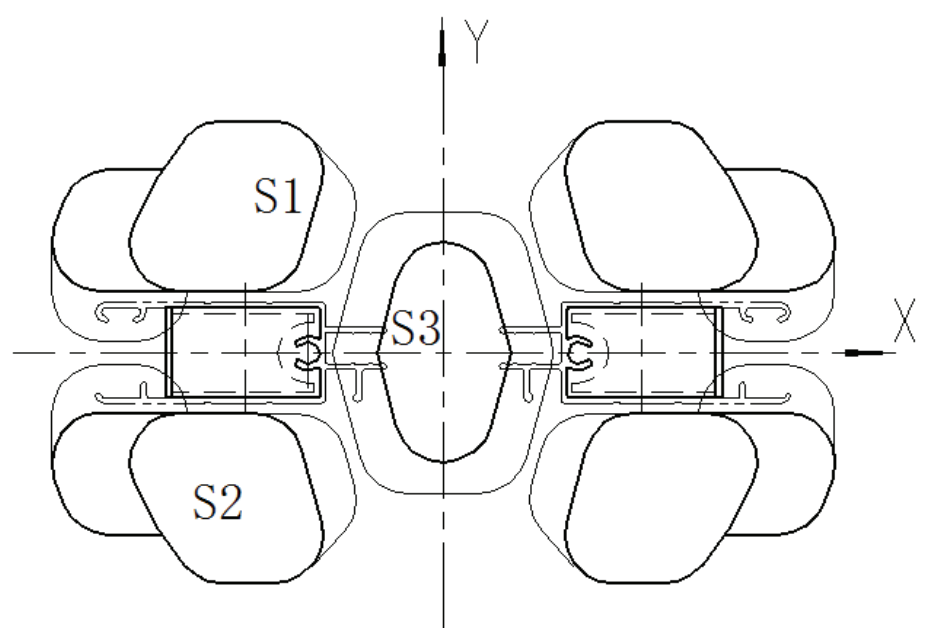

Figure4. The signal of portholes

To design a common feeder port in the die center is to consider that the screw hole in the core is a difficult part of metal forming, It is necessary to ensure that there is sufficient metal flow supply.

The main parameters are as follows:

1. The feeding ratio is 14.5 .

Considering the surface quality of the profiles and the extrusion force during the extrusion process, the experience shows that The most appropriate is that the ratio is $(25 \sim 35) \%$ of the extrusion ratio. Therefore, using computer simulation software and personal experience, the final feeding ratio value is appropriate.

2. The width of hollow bridge are $20 \mathrm{~mm}$ and $16 \mathrm{~mm}$ respectively.

3. The height of the hollow bridge named male die thickness is $65 \mathrm{~mm}$.

On the premise of guaranteeing the strength, the die thickness of male die should not be too large, otherwise, the extrusion pressure will increase, it will be unfavorable to the forming and the strength.
4. The area relationship between the feeder ports is as follows:

$$
\mathrm{S} 1=\mathrm{S} 2=1.35 \mathrm{~S} 3
$$

Through software simulation, it is found that S1, S2 and S3 meet the area relationship shown in Equation 2, the flow velocity tends to be consistent everywhere, the $\mathrm{S} 3$ value increases, the metal flow is intense and the deformation degree is bigger, the elastic offset of the die core in the radial direction will increase.

$$
\mathrm{S} 1=\mathrm{S} 2=(1.2 \sim 1.4) \mathrm{S} 3
$$

5. The largest feeder ports diameter of feeding is $110 \mathrm{~mm}$.

6. The outlet of the feeder ports adopt the reaming form of 10.5 degrees. The main reason is to reduce the extrusion force. The extrusion pressure can be reduced by about $5 \%$ by adopting 5 15 degree reaming.

7. This is the obvious difference that no feeder ports are arranged on the side of the cutting plane between the twin cavities and the single cavity of the semi hollow profile. If a feeder port is set on one side of the cutting plane, it is difficult for the metal to converge. 


\subsection{Assembly of die and cantilever}

The assembly of die and cantilever are shown in figure 5 .

In a single cavity die, the joint of the cantilever in the die is usually the form of a vertical plane, which is easy to move the metal into the gap of the joint plane, the metal will be formed in the joint plane and the surface of profile will appear a raised wire or convex surface.
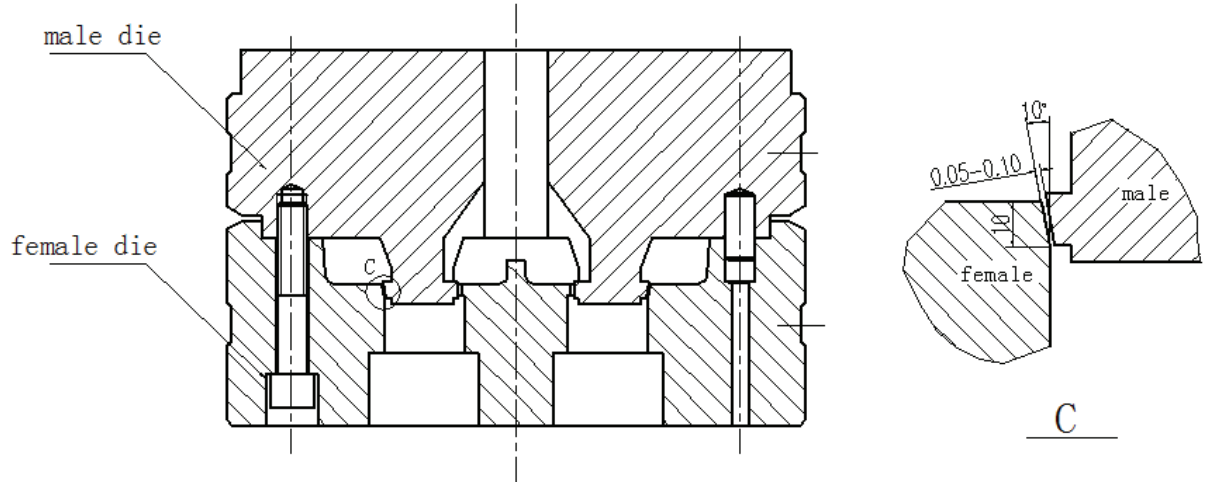

Figure5. The assembly of die and cantilever

In order to eliminate the phenomenon, and prevent the collision of cores in the assembly process with the increase of the cores, the oblique plane jointing is designed. In this way, it overcomes the shortcomings of the vertical jointing, the direction of metal flow and the jointing plane is formed into an angle, the metal will be cut so that the phenomenon of raised wire and convex surface will disappear. Thus, the bonding plane is not parallel to the direction of the metal flow to form a shearing of the metal, thereby preventing the possibility of the metal entering the gap of the joint surface. The practice shows that the effect is good.

\subsection{Design of female die}

The design of female die include welding chamber height, shape, structure and the choice of bearing.

The welding chamber structure and bearing as shown in figure 6.
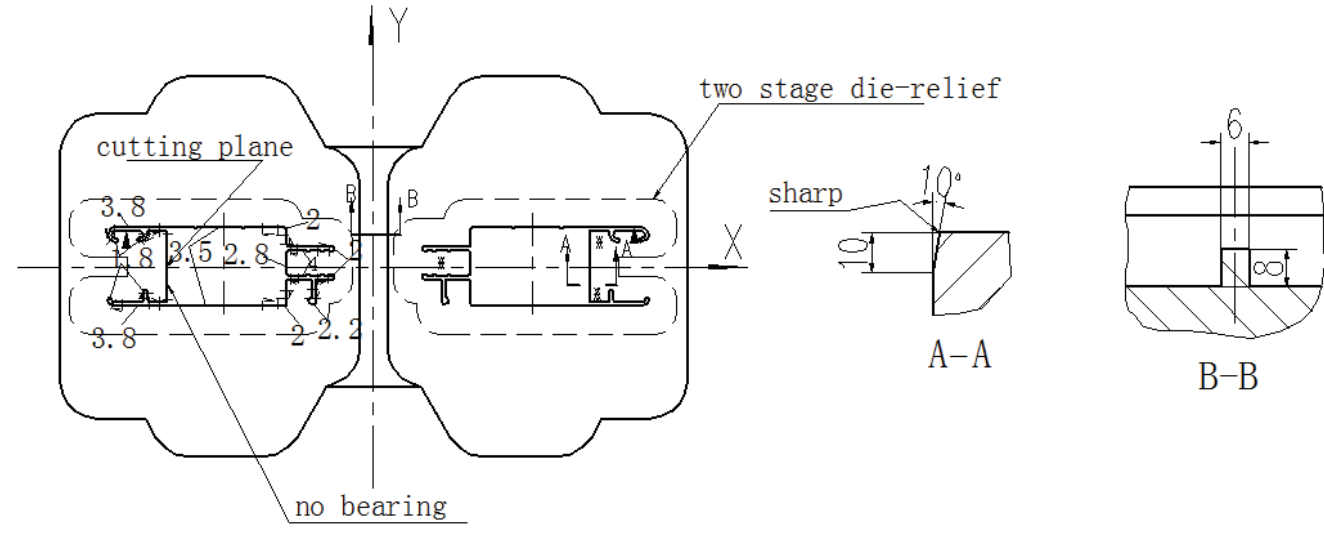

Figure6. The signal of welding chamber and the bearing

The main parameters are as follows:

1.About the welding chamber shape

The welding chamber shape is to base on the largest edge of feeder ports as the contour that ensure the metal in the welding chamber from the feeder ports that it can be not blocked on the boundary. Usually, the welding chamber contour edge must be bigger $2 \mathrm{~mm}$ than edge of the portholes, and the piers shall be formed as far as possible at the root of the portholes to increase the strength of the die.

2.The welding chamber height is $16 \mathrm{~mm}$.

3.About the structure of the welding chamber

It is an important principle that the independent welding chambers are designed for the die design of multi cavities. A separating wall of $6 \mathrm{~mm}$ in width between the welding chambers is arranged. If the partition wall is not arranged, the rigid region of metal flow is formed at the central part between the die holes, and the coarse crystal phenomenon of the corresponding section of the section bar is easy to occur, which leads to serious chromatic aberration of the section bar.

4.About the selection of bearing

For the die with twin cavities, according to the principle of selecting bearing of the single, the bearing of one die hole is selected, and the bearing of the other die hole is the same.

\section{Conclusions}

The die has been tested and used, the result indicates that the die has been successful at one time. Its extrusion 
output life of $20.3 \times 10^{3} \mathrm{Kg}$, all indicators meet the requirements. This shows that the structure used in the case of semi hollow profiles is effective and reasonable. It can also be concluded that if a single hole extrusion is applied on the same extrusion machine, the extrusion coefficient is 111.6 , which will be difficult to carry out. And smaller extrusion machine must be selected. This shows that extrusion die with twin cavities can improve production efficiency and reduce cost.

\section{References}

1. LIU Jingan. Die design, manufacture, application and maintains for aluminum profiles extrusion[M].Beijing:Metallurgical

Press, 1999:181 183.

2. XIE Jianxie,LIU Jingan, Die design, manufacture, application and maintains for aluminum profiles extrusion[M].Beijing:Metallurgical

Press, 2012:133 138

3. WANG Liwei. Optimization design of extrusion die for the bigger slenderness ratio half hollow aluminum profile $[\mathrm{J}]$. Die and Mould Manufacture, 2011(4):61-64.
4. YU Mingtao,LI Fuguo.Simulation extrusion process of the sketch hollow aluminum profile based on infinite volume method[J].Die and Technology, 2008(4):40-43.

5. SUN Xuemei,ZHAO Guoqun.Fake porthole extrusion die structure design and strength analysis for cantilever aluminum alloy profiles[J].Journal of Mechanical Engineering,2013, 49(24):39 44.

6. KUANG Weihua,CHEN Biaobiao.Research on design and structure of extrusion die for cantilever aluminum profile [J].Hot Working Technology,2013,42(21):136-138.

7. DENG Rurong, Huang,Xuemei. Design of the extrusion die of semi-hollow aluminum profile[J].Light Alloy Fabrication Technology,2015,43(4):51-54.

8. $\mathrm{Xu}$ Yongli, Huang Shuangjian, Pang Zugao, et al.Failure analysis of extrusion die and optimization of heat treatment process for aluminum alloy circular tube $[\mathrm{J}]$. Forging \& Stamping Technology, 2015, 40(2):116-122.

9. Hu Dongpo, Wang Leigang, Huang Yao. Steadystate simulation and die improvement on the extrusion of prolate aluminum profile [J]. Forging \& Stamping Technology, 2015, 40(4):69-73. 